\title{
0 ensino de Matemática nos Anos Finais e a ludicidade: 0 que pensam professora e alunos?
}

\author{
The teaching of Mathematics in the Final Years and playfulness: what do \\ teachers and students think?
}

\author{
Américo Junior Nunes da Silva \\ Ilvanete dos Santos de Souza \\ Idelma Souza da Cruz
}

\begin{abstract}
Resumo: 0 presente estudo é um recorte de uma investigação que objetivou compreender a presença da ludicidade e suas repercussões no processo de construção do conhecimento matemático. Para esse artigo, no entanto, apresentaremos as percepções de professor e alunos quanto ao lúdico nos processos de ensino e de aprendizagem da Matemática. Quanto ao percurso metodológico, trata-se de uma pesquisa empírica, de abordagem qualitativa, que, em seu processo de produção de dados, contou com a utilização de questionários e com a realização de oficinas temáticas. Para analisar os dados nos inspirou a análise de conteúdo apresentada por Bardin (1977). Nesse recorte, nos ateremos apenas aos questionários. Esse trabalho trouxe evidências do potencial da ludicidade enquanto ferramenta que contribui para o ensino e aprendizagem, e que cabe às universidades repensar, também, seus cursos de formação de professores buscando incluir o lúdico numa perspectiva de formação.
\end{abstract}

Palavras-chave: Lúdico. Educação Matemática. Ensino e Aprendizagem. Percepções.

Abstract: The present study is an excerpt from an investigation that aimed to understand the presence of playfulness and its repercussions in the process of construction of mathematical knowledge. For this article, however, we will present the perceptions of teachers and students regarding playfulness in the teaching and learning process of Mathematics. As for the methodological path, it is an empirical research, with a qualitative approach that, in its data production process, relied on the use of questionnaires and thematic workshops. To analyze the data, the content analysis presented by Bardin (1977) inspired us. In this cut, we will stick only to the questionnaires. This work brought evidence of the potential of playfulness as a tool that contributes to teaching and learning, and that it is up to Universities to also rethink their teacher training courses, seeking to include playfulness in a training perspective.

Keywords: Ludic. Mathematical Education. Teaching and learning. Perceptions.

Américo Junior Nunes da Silva Doutor em Educação. Professor do Programa de Pós-Graduação em Educação, Cultura e Territórios Semiáridos da Universidade do Estado da Bahia. Bahia, Brasil.

(iD) orcid.org/0000-0002-7283-0367 $\triangle$ amerjun2005@hotmail.com Ilvanete dos Santos de Souza Doutoranda em Educação (UFBA). Técnica Pedagógica da Secretaria Municipal de Educação de Barreiras. Bahia, Brasil. (iD) orcid.org/0000-0001-6036-834X $\triangle$ Ilvanetess@gmail.com Idelma Souza da Cruz Licenciada em Matemática pela Universidade do Estado da Bahia (UNEB). Bahia, Brasil. (iD) orcid.org/0000-0001-9521-0657 \idelmacruzuneb@gmail.com 


\section{Introdução}

Atualmente, é perceptível que os alunos estão cada vez mais atualizados e envolvidos com as inovações postas, e isso foi notado ao longo de nossas experiências com os Estágios Supervisionados e o Programa Institucional de Bolsa de Iniciação à Docência (PIBID), por exemplo. A escola e os seus professores, portanto, não devem ficar obsoletos e precisam tentar acompanhar, se possível, incorporando algumas dessas inovações às suas aulas.

Quando falamos em inovação, sobretudo, não nos referimos apenas às questões tecnológicas, embora o termo nos sugira isso. Mesmo sabendo que as discussões voltadas ao uso de jogos, brincadeiras, músicas, por exemplo, não são tão atuais, reconhecemos que a incorporação desses instrumentos, em sala de aula, ainda é algo que precisa ser verdadeiramente realizado (ALVES, 2001; SANTOS e CRUZ, 2011; SÁ et al., 2013).

Se tratando do ensino de Matemática e tendo em vista pesquisas realizadas em programas de pós-graduação da área de Educação e Ensino de Matemática no país, como destaca Silva e Passos (2020), percebemos ser comum investigar a vivência de experiências lúdicas e suas implicações para os processos de ensino e de aprendizagem. Em alguns desses trabalhos de pesquisa, por exemplo, fica evidente que essas práticas, quando bem planejadas, contribuem para o ensino de conceitos matemáticos.

No entanto, sabemos que, infelizmente, muitos professores desconhecem o real sentido da ludicidade de maneira que o percebem, muitas vezes, como espaço para recreação e passatempo, e não como construtores de conhecimentos matemáticos (SILVA, 2014). Entendemos que o desconhecimento do que é a ludicidade implica, sobretudo, na não incorporação do método nas práticas pedagógicas cotidianas.

Foi a partir da provocação apresentada anteriormente, o fato de muitos professores desconhecerem o significado do conceito, que nos mobilizamos para a realização desse estudo. Alguns questionamentos iniciais nos provocavam, como o que pensam os professores que ensinam Matemática nos anos finais do Ensino Fundamental acerca da Ludicidade? e, além disso, o que pensam os estudantes?

Essa pesquisa configura-se importante para a Educação Básica por permitir que o lugar da ludicidade no ensino da Matemática, nos Anos Finais do Ensino Fundamental, seja repensado e que pré-conceitos existentes, quanto ao uso de atividades potencialmente lúdicas para trabalhar os conceitos matemáticos e como potencializador das aprendizagens, sejam ressignificados pelos 
professores e alunos. Um ponto inovador do estudo é permitir que as vozes dos estudantes e as suas percepções quanto ao uso desse tipo de atividade sejam ouvidas.

Este artigo, portanto, tem como objetivo identificar as percepções do professor e alunos quanto ao lúdico nos processos de ensino e de aprendizagem da Matemática. Trazemos, na escrita deste texto, reflexões a respeito da ludicidade e do ensino de Matemática, buscando enfrentar, como nos apresentam D'Ambrosio (1996) e Santos e Cruz (2011), os inúmeros desafios postos à Educação, por meio da aceitação das inovações e da necessidade de assumir novas práticas.

\section{Discussão teórica}

A Educação é uma área em que muitos e diferentes desafios são, cotidianamente, encontrados. Portanto, a formação de educadores precisa ser pensada para enfrentar os diferentes problemas postos pela sociedade na contemporaneidade.

Embora partamos do senso comum de que o processo educacional deve ser inovador e que também o professor, em sua prática pedagógica, precisa utilizar novos métodos de ensino, observou-se que alguns cursos ${ }^{1}$, embora já sinalizem esse aspecto como importante para a formação, no "chão da sala de aula"2, pouco tem sido de fato incorporado.

Nessa direção, portanto, Santos e Cruz (2011) destacam que quando nos referimos à Educação, precisamos saber que são muitos os desafios a serem enfrentados para que esta área possa ser considerada como geradora dos avanços científicos. Ao compará-la com outros setores, como a Medicina, Engenharia ou Informática, por exemplo, nas quais as inovações aparecem com frequência, perceberemos que nos últimos 50 anos pouco aconteceu, de modo que os avanços ocorridos não chegaram a reverter o processo como um todo.

Destarte, "o mundo atual está a exigir outros conteúdos, naturalmente outras metodologias, para que se atinjam os objetivos maiores de criatividade e cidadania plena" (D’AMBRÓSIO, 1998, p. 20). É preciso, para isso, como aponta D'Ambrosio (1993), valorizar as diferentes formas de se matematizar, repensar constantemente o ensino de Matemática a partir

\footnotetext{
1 Para essa construção, portanto, levamos em consideração as nossas vivências de pesquisa e formação, uma vez que somos pesquisadores e os dois primeiros autores formadores de professores que atuaram em diferentes instituições no Estado da Bahia.

2 Termo que usamos para definir a realidade das escolas públicas brasileiras.
} 
de novas práticas e, sobretudo, refletir sobre a formação inicial promovida pelos cursos de Licenciaturas aos futuros professores.

Diante do cenário da necessidade de novas práticas e da valorização das diferentes formas de matematizar, visualizamos as atividades potencialmente lúdicas como possibilidades de desenvolvimento do sujeito. Diferentemente da forma como é concebida por muitos, o uso de ferramentas com tal potencial não é algo que se destina apenas ao trabalho com crianças, como nos apresenta Huizinga (2012), corroborando ao que destacam Santos e Cruz (2011). Como sinalizam os autores, o uso de atividades dessa natureza contribui para o desenvolvimento pessoal, social e cultural e facilita a aprendizagem, independente da idade e da etapa de ensino.

Nesse sentido, consideramos importante pontuar o que entendemos, até o presente momento de escrita desse artigo, por lúdico, tendo em vista a importância do termo para este trabalho. A esse respeito, como nos apresenta Santos e Cruz (2011), a palavra lúdico vem do latim ludus e significa brincar. Nesse brincar inclui-se os jogos, brinquedos e divertimentos "e é relativa também à conduta daquele que joga, que brinca e que se diverte. Por sua vez, a função educativa do jogo oportuniza a aprendizagem do indivíduo, seu saber, seu conhecimento e sua compreensão de mundo" (SANTOS e CRUZ, 2011, p. 9).

Nesse sentido, embora o termo muitas vezes nos remeta a inferir que o lúdico se relaciona única e exclusivamente ao jogo e a brincadeira, como nos apresenta Silva (2014), precisamos esclarecer que esses são alguns dos instrumentos que podem fazer com que o sujeito tome a atividade como lúdica.

Mas como assim tomar a atividade como lúdica? Até aqui abordamos as atividades como sendo potencialmente lúdicas. O uso do termo potencialmente é para marcar, ainda a partir das premissas presentes em Silva (2014) e Silva e Passos (2020), que há uma subjetividade no processo de percepção de algo como lúdico. Na percepção de alguma atividade dessa natureza, mobilizamos questões pessoais e subjetivas, as quais são movimentadas pelas nossas histórias de vida. Por exemplo: determinadas músicas marcam mais que outras por nos fazerem rememorar fatos, assim como objetos, ou ainda, um jogo pode dar prazer para um jogador e não para outro.

Queremos, de certo modo, desconstruir a percepção de que o lúdico é apenas o jogo e a brincadeira. Fortuna (2001), por exemplo, destaca que uma aula ludicamente inspirada não é aquela que traz alguma dessas atividades, mas sim aquela que se apresenta e embute as características do brincar. Dessa forma, mesmo sem levar qualquer instrumento, há possibilidade 
de os estudantes perceberem uma aula como lúdica. Como? Talvez, as formas como o professor desencadeia as discussões, o tom de voz usado ou como apresenta os problemas contribuam para isso.

Embora Moura (2011) refira-se exclusivamente ao jogo ao destacar que este está carregado de conteúdo cultural e que o seu uso requer certo planejamento que considere os elementos sociais em que se insere, entendemos que podemos relacionar essa construção às inúmeras ferramentas com potencial lúdico, que precisam ser vistas "como conhecimento feito e também se fazendo. É educativo. Esta característica exige o seu uso de modo intencional e, sendo assim requer um plano de ação que permita a aprendizagem de conceitos matemáticos e culturais, de uma maneira geral" (MOURA, 2011, p. 89).

Utilizar esses diferentes instrumentos potencialmente lúdicos, como nos sinalizam Alves (2001), Sá e Silva (2013), Silva (2014) e Silva e Passos (2020), é fazer com que se estimule as relações, principalmente afetivas e sociais, além de promover atitudes críticas, fazendo as mediações entre os alunos e o conhecimento. Sem dúvidas, a utilização da ludicidade nas aulas, seja ela de Matemática ou de qualquer outra disciplina, configura-se como uma possibilidade interessante, principalmente porque não se precisa de muito para propô-las.

A educação lúdica está distante da percepção ingênua de passatempo, brincadeira vulgar, diversão superficial, como bem nos apresenta Almeida (1998). Ela não é ação exclusiva da criança, pelo contrário, o adolescente, o jovem e o adulto incluem-se nessa relação, de forma que "aparece sempre como uma forma transacional em direção a algum conhecimento, que se redefine na elaboração constante do pensamento individual em permutações com o pensamento coletivo" (ALMEIDA, 1998, p. 13).

Quando pensamos em novas práticas para o ensino de Matemática, muitos recorrem, quase que intuitivamente, ao uso de instrumentos potencialmente lúdicos ou ao que entendem por eles, por exemplo, "o uso de jogos e curiosidades no ensino da Matemática tem o objetivo de fazer com que os alunos gostem de aprender essa disciplina, mudando a rotina da classe e despertando o interesse do aluno" (SILVA et al. 2013, p. 6). Espera-se, como sinalizam Muniz (2016) e Silva (2014), que o lúdico possibilite uma aproximação com a Matemática e, consequentemente, uma aprendizagem prazerosa e divertida.

Quando se trata do aprendizado de Matemática, é importante que as diferentes ferramentas com potencial lúdico sejam revestidas com significado e bem planejadas, levando-se 
em consideração as particularidades dos sujeitos com quem se trabalhará. Isso, de certo modo, nos leva a pensar sobre a necessidade de problematizar a própria formação de professores, afinal, desse professor ou futuro professor espera-se o conhecimento dessa ferramenta e uma ação consciente em relação ao seu uso. O uso de material didático, como destaca Lorenzato (2010), é um bom intermediador para a construção do conhecimento matemático, porque, a partir do palpável, conseguimos atingir as abstrações necessárias no ensino e na aprendizagem da Matemática.

Para discutir teoricamente as questões que envolvem a aprendizagem nos respaldaremos na perspectiva sócio-histórica, por entender ser ela a mais apropriada para explicar esse contexto de aprender a partir das atividades potencialmente lúdicas. Nesse sentido, como descreve Fernandes (1997, p. 563), fundamentando-se em Vygotsky, o desenvolvimento conceitual se dá por meio da interação entre os conceitos naturais ou conceitos espontâneos e o sistema de conceitos científicos, ou seja, os alunos aprendem a partir dessa relação.

A perspectiva de aprendizagem apresentada anteriormente vai ao encontro do que discutimos quanto ao lúdico e o lugar que ocupa na significação dos conceitos matemáticos pelos sujeitos. Entendemos que as atividades potencialmente lúdicas promovem um espaço de desenvolvimento conceitual por permitir, no movimento da própria atividade lúdica, que os estudantes relacionem os conceitos naturais ou espontâneos, construídos por eles em espaços escolares e não escolares, no movimento do jogar/brincar/interagir coletivamente com o outro, de forma a construir novos conhecimentos matemáticos.

Vale destacar que entendemos esse movimento de ensinar Matemática por meio de atividades lúdicas como dinâmico. Cada estudante participa de forma particular e diferente, apresentando formas diversificadas e enriquecedoras para lidar com os problemas que são postos no movimento do jogo/brincadeira/interação (SILVA, 2014). Nesse sentido, é importante que os professores entendam essa dinâmica e saibam como se comportar de forma a garantir as aprendizagens matemáticas.

Nesse sentido, "a formação inicial deve fornecer as bases para poder construir um conhecimento pedagógico especializado" (IMBERNÓN, 2009, p. 65). Percebe-se que, atualmente, como nos apresenta Santos e Cruz (2011), a formação de professores, principalmente daqueles que ensinarão Matemática, não está satisfazendo as grandes necessidades demandadas pela contemporaneidade. 
O lúdico, embora discutido e aceito enquanto metodologia de ensino, não tem sido visto por muitos cursos na sua dimensão de formação e percebido enquanto promotora de uma formação lúdica3. Muitos professores, por não terem sido preparados para isso, acabam não planejando coerentemente suas atividades que envolvem aspectos da ludicidade e as apresentam muitas vezes sem uma articulação para uma aprendizagem que vise os significados e a formação humana do educando.

O professor, ainda em sua formação inicial, deveria compreender os diferentes aspectos que interagem para o trabalho com a ludicidade e não pensá-la apenas enquanto ferramentas que motivam os alunos. Para o ensino e aprendizagem da Matemática, por exemplo, a ludicidade deve criar um canal que permita uma aproximação para aprender a ver a própria Matemática como lúdica, de forma a alunos e professores divertir-se e sentirem prazer no ato de matematizar.

Dessa maneira, a formação lúdica pode conferir à conformação inicial um auxílio pedagógico, de forma a ganhar qualidade, mediante, segundo Santos e Cruz (2011), principalmente, a presença dos três pilares: a formação teórica, a formação pedagógica e como inovação a formação lúdica.

A formação lúdica, esse aspecto inovador que os autores apresentam, possibilita "ao futuro educador conhecer-se como pessoa, saber de suas possibilidades e limitações, desbloquear suas resistências e ter uma visão clara sobre a importância do jogo e do brinquedo para a vida da criança, do jovem e do adulto" (SANTOS e CRUZ, 2011, p. 14).

Vale ressaltar que a utilização de atividades lúdicas é importante, no entanto, apenas o seu uso, por si só, não garante uma aprendizagem da Matemática com significado. O professor, como nos apresentam Fiorentini e Miorim (1990), não pode subjugar sua metodologia de ensino a qualquer tipo de material porque ele é atraente ou potencialmente lúdico; nenhum material é válido por si só, ou seja, "os materiais e seu emprego sempre devem, estar em segundo plano. A simples introdução de jogos ou atividades no ensino da Matemática não garante uma melhor aprendizagem desta disciplina" (p. 4).

\footnotetext{
${ }^{3} 0$ que entendemos por formação lúdica nesse trabalho? "A formação lúdica se assenta em pressupostos que valorizam a criatividade, o cultivo da sensibilidade, a busca da afetividade a nutrição da alma, proporcionando aos futuros educadores vivências lúdicas, experiências corporais, que se utilizam da ação, do pensamento e da linguagem, tendo no jogo sua fonte dinamizadora" (SANTOS, 1997, p. 13).
} 


\section{Percurso metodológico}

A metodologia do presente estudo é de cunho empírico, a qual refere-se à produção prioritária dos dados inteiramente com os participantes, produzindo-os com base no contexto investigado (BERG, 2000). Constrói-se a partir de uma perspectiva qualitativa (GIL, 2002), tendo em vista uma abordagem exploratória, uma vez que se procurou conhecer melhor o que pensam os participantes a respeito da ludicidade e do ensino de Matemática.

Segundo Gil (2002, p. 41), pesquisas dessa natureza "têm como objetivo proporcionar maior familiaridade com o problema, com vistas a torná-lo mais explícito ou a constituir hipótese". Ainda segundo o autor, estas pesquisas objetivam, principalmente, aprimorar ideias e o seu planejamento é bastante flexível, principalmente em relação aos diversos instrumentos de produção de dados, de modo a considerar os mais variados aspectos relativos ao fato estudado.

Para a realização da pesquisa, portanto, escolhemos uma escola municipal situada na zona rural do município de Cristópolis, na Bahia. A escolha se deu, sobretudo, tendo em vista a facilidade de acesso para um dos pesquisadores que já havia desenvolvido atividades nessa localidade.

A pesquisa foi realizada com uma professora de Matemática do $9^{\circ}$ ano e com cinco alunos de umas de suas turmas. A escolha de apenas cinco alunos se deu pelo fato da dificuldade dos outros virem em turno aposto, já que moravam distantes da escola e tinham dificuldades de deslocamento nos horários nos quais foram realizadas as oficinas temáticas. Os cinco alunos participantes, de outra parte, residiam no povoado e aceitaram participar da pesquisa.

Para a escrita desse artigo, como já evidenciamos anteriormente, levamos em consideração o primeiro objetivo específico da pesquisa: identificar as percepções dos professores e alunos quanto ao lúdico nos processos de ensino e de aprendizagem da Matemática.

Para atender tal objetivo e tentar identificar as percepções tanto da professora quanto dos alunos, foi aplicado um questionário 4 para a professora e dois questionários ${ }^{5}$ para os alunos — um

\footnotetext{
4 Esse questionário foi construído levando-se em consideração quatro eixos: i) formação e atuação profissional; ii) 0 que entendem por Matemática e como tem a trabalho; iii) o que entendem por lúdico e se promove a utilização de ferramentas com potencial lúdico em suas aulas; iv) o que tem, e como tem, ensinado de Geometria e Geometria Espacial.

${ }^{5}$ Esses questionários foram construídos tendo em vista os seguintes eixos: i) o que entendem por Matemática e como tem sido o trabalho com ela; ii) o que entendem por lúdico e como tem sido a utilização de ferramentas com potencial lúdico nas aulas para eles; iii) o que e como eles têm trabalhado com os conteúdos de Geometria.Com o primeiro questionário quis-se entender o que eles traziam de percepções das suas vivências escolares anteriores. 0 segundo
} 
antes e outro depois das oficinas. Vale ressaltar que a professora e os responsáveis legais pelos estudantes, uma vez que eram menores de idade, assinaram o Termo de Consentimento Livre e Esclarecido (TCLE) para sua participação.

Após a aplicação do questionário inicial e a produção de dados para a pesquisa, realizamos oficinas levando em consideração os principais conteúdos de Geometria. Como nosso objetivo, para este artigo, não é discutir as oficinas em si, não as apresentaremos na íntegra. No entanto, consideramos importante pontuar que foi realizada com a presença de materiais potencialmente lúdicos. Após a vivência nas oficinas, reaplicamos o questionário para identificar as mudanças nas percepções dos alunos depois de sua realização.

Os questionários apresentaram perguntas objetivas, as quais foram tabuladas buscando identificar as percepções ${ }^{6}$ dos participantes em relação ao foco de investigação dessa pesquisa: o ensino de Matemática e a ludicidade.

Para a análise dos dados obtidos nos questionários foi usado a técnica de Análise do Conteúdo, definida por Bardin (1977) como um conjunto de técnicas de análise das comunicações, objetivando obter procedimentos sistemáticos e objetivos de descrição do conteúdo das mensagens indicadores - quantitativas ou não —, que possibilitem a inferência de conhecimentos relativos às condições de produção/recepção — variáveis inferidas — destas mensagens.

\section{Análise dos dados}

\subsection{Análise do questionário com a professora}

O questionário, utilizado como instrumento de pesquisa e realizado com a professora, foi composto de 10 questões, entre as quais questionamos a respeito de sua formação. Foi possível observar que a profissional tem nível superior em Licenciatura em Biologia; exerce a profissão há nove anos; e atua com as mais diversas disciplinas, sendo que a maior identificação é com a Matemática. Trabalha em uma única escola pública no turno vespertino com uma média de 36 alunos por sala.

questionário foi construído tendo como base as oficinas que foram realizadas, mas seguiram os mesmos eixos apresentados anteriormente.

${ }^{6}$ Vale destacar que entendemos por percepção, fundamentando-se em Penna (1997), como 0 ato de conhecer objetos e situações por meio dos sentidos. Trata-se, ainda segundo a autora, de um termo usado frequentemente para expressar opinião ou atitude. 
Infelizmente, mesmo após algumas iniciativas do Ministério da Educação, como o Plano Nacional de Formação de Professores da Educação Básica (PARFOR), por exemplo, que ofereceu o curso de Matemática para os professores da rede de ensino que não possuíam formação, mas lecionavam a disciplina, percebemos que ainda não haver professores que continuam atuando em áreas diferentes de suas formações iniciais.

Sabemos que o fato de não ter feito uma formação inicial em Matemática traz implicações para a forma como concebe e ensina tal disciplina. Nessa direção, optamos por questioná-la sobre o que entende por Matemática. Segundo a professora, "é uma disciplina útil para inúmeras atividades em nosso cotidiano. Sempre utilizamos nossos conhecimentos matemáticos e nem percebemos. Ela nos traz muitos benefícios".

A sua forma de conceber a Matemática e relacioná-la às atividades úteis e cotidianas se aproxima do que nos apresenta Soares (2009), que sinaliza que a disciplina faz parte de inúmeras atividades do nosso cotidiano. Ficamos nos perguntando, a partir de então, como a professora mobiliza tais conhecimentos para que os estudantes o percebam dessa forma, uma vez que não estudou o objeto matemático como deveria em sua formação inicial.

Ao trabalhar com alunos, principalmente de Ensino Fundamental, percebemos, e para isso fazemos uso de nossas experiências profissionais, que muitos sentem dificuldades na disciplina e a considera um "bicho de sete cabeças" que nunca vão aprender. Dessa forma, por considerar uma realidade comum hoje, os educadores devem procurar meios para tentar aproximar os estudantes do conhecimento matemático. Sendo assim, quando questionada sobre isso, a professora discute ser "difícil desenvolver a Matemática de forma rica para todos os alunos se enfatizarmos uma linha metodológica única. Faço uso de jogos e o trabalho em grupo".

Conforme a resposta da professora, percebe-se que para tentar sanar as dificuldades apresentadas pelos alunos e mudar a realidade de distanciamento do conhecimento, faz uso, muitas vezes, de jogos e de atividades em grupo. Há um reconhecimento, por parte dela, da tentativa de diversificar as abordagens metodológicas. Vemos aqui, claramente, uma constatação dos diferentes ritmos e tempos de aprendizagem. Isso, como nos apresenta Silva, Nascimento e Muniz (2017), implica, possivelmente, que a produção matemática dos estudantes seja valorizada.

A professora encontra no jogo apoio para a sua prática pedagógica. Nesse sentido, como nos apresenta Moura (2011), quando o jogo, em Educação Matemática, promove a aprendizagem, pode ser considerado um material de ensino. Para isso, como ainda nos apresenta a professora, 
é difícil seguir um único instrumento metodológico, mas é preciso diferenciar e permitir que as diferentes realidades, tempos e ritmos de aprendizagem sejam respeitados.

Não podemos deixar de destacar que, como salientam Muniz (2016) e Silva (2014), não é o jogo por si só que cumpre o papel de ensinar Matemática. É importante, nesse contexto, que o professor consiga mobilizar situações de aprendizagem, pode ser por situações-problema promovidas pela própria atividade, que permitam aos estudantes aprender de fato. Para isso, fazse necessário que o professor conheça profundamente a Matemática e consiga interagir nesse movimento dinâmico de ensinar e aprender. Em nosso caso, por exemplo, temos uma professora que não fez a formação inicial na área de atuação e isso pode ser um fator que pontua negativamente para o uso adequado desse tipo de atividade.

Hoje em dia, com os jovens bastante atualizados, faz-se necessário que escolas e professores também se renovem e procurem metodologias que possam favorecer um aprendizado com significado. Ao perguntar à professora sobre as metodologias utilizadas, ela responde: "uso reflexão e discussão. Esses são elementos fundamentais no ensino da Matemática. $E$ trabalho com problemas desafiantes e reais".

A própria Base Nacional Comum Curricular (BRASIL, 2017), por exemplo, apresenta a resolução de problemas como o cerne do ensino de Matemática. No entanto, tendo em vista 0 advento da tecnologia, por exemplo, que prende muitas vezes a atenção dos alunos, queríamos saber como esses problemas são apresentados no ambiente da sala da aula. Segundo a professora, "sempre procuro atrair a atenção do aluno, muitas vezes recorro aos jogos, uma maneira eficaz levando o aluno a pensar".

Percebemos que a profissional encontra nos jogos uma maneira de atrair a atenção dos alunos. Ao debater o uso de jogos, a BNCC (BRASIL, 2017) considera que são uma maneira interessante de propor problemas, pois é um método atrativo que favorece a criatividade, sua elaboração e resolução.

Como percebemos que a ludicidade se faz presente nas práticas da professora por meio de jogos, como ela nos relatou, perguntamos sobre o que entende por lúdico. Segundo ela, "são formas de desenvolver a criatividade, os conhecimentos, através de jogos, músicas e danças. O intuito é ensinar divertindo e interagindo com os outros".

Interessante que a professora, contrariando o que comumente é feito, de definir o lúdico como o jogo e a brincadeira, como nos apresenta Silva (2014), não o vê apenas como um jogo, 
mas sim como atividades que desenvolvem a criatividade e os conhecimentos dos alunos, além de promover a interação dos mesmos, os quais aprendem se divertindo. De acordo com Santos e Cruz (2011), o lúdico vai muito além de apenas diversão, pois facilita a aprendizagem e desenvolve a relação pessoal, social e cultural, além de colaborar para uma boa saúde mental e de socialização, comunicação, expressão e construção do conhecimento.

Muitos educadores acham que a utilização do lúdico não contribui com a aprendizagem matemática e que só causam indisciplina na sala de aula, no entanto, ao questionar a professora sobre esse aspecto, ela se posiciona apresentando a ludicidade como algo que "desenvolve a criatividade, sociabilidade, enriquece o relacionamento entre os alunos, reforça os conteúdos já estudados, adquire novas possibilidades e proporciona também a concentração". Pela sua resposta, fica visível encontrar no lúdico uma ferramenta metodológica que pode ser utilizada para reforçar conteúdos já estudados, além de possibilitar e proporcionar a concentração, a criatividade e a sociabilidade dos alunos. Além de reforçar, é importante perceber a utilização das diferentes ferramentas potencialmente lúdicas como construtoras, também, de novos conhecimentos.

Ao ser questionada sobre a utilização do lúdico em suas aulas de Matemática, a professora responde: "sempre procuro reforçar a aprendizagem do aluno, mudando a rotina utilizando jogos, como dominó, quebra cabeça e tabuleiros". Percebe-se aqui, mais uma vez, que concebe os jogos como forma de reforçar o que, muitas vezes, é trabalhado de forma expositiva. É importante, como já dissemos, que as diferentes ferramentas potencialmente lúdicas sejam pensadas no intuito de possibilitar que conceitos matemáticos sejam construídos.

A professora, pelo que foi respondido, apresenta uma percepção a respeito do uso do lúdico em sala de aula como algo que contribui para um melhor aprendizado, pois é um método novo que os alunos gostam. Alves (2001), corroborando o que apresentou a professora, entende que, ao utilizar o lúdico na escola, proporciona-se uma retomada cultural, a partir da qual a criança traz para a escola vivências que teve fora do ambiente escolar.

Quando questionada sobre o comportamento dos alunos quando leva algo potencialmente lúdico para a sala de aula, ou seja, se percebe alguma diferença no comportamento deles, responde que "sim. Além de melhorar o relacionamento entre alunos, desperta o interesse pela Matemática, melhora a concentração, criatividade, o raciocínio lógico etc.". Nesse sentido, Smole, Diniz e Milani (2007) esclarecem que quando os alunos jogam, eles estão sempre procurando uma 
melhor maneira de fazê-lo e de resolver problemas, refletindo e analisando as regras e estabelecendo uma relação entre o jogo e os conceitos do conteúdo abordado. Quando levamos esse tipo de atividade não podemos perder de vista uma coisa: a aprendizagem da Matemática.

Se tratando do ensino de Matemática, com foco na Geometria, percebe-se que muitos alunos sentem dificuldades em alguns de seus conteúdos, pois é nesse momento que eles têm de passar do espaço em que vivem para o espaço pensado, abstrato. Quando perguntamos se a professora já havia trabalhado Geometria com esses alunos, ela respondeu que "sim. Pontos e retas, retas paralelas, ângulos e polígonos".

Percebe-se, então, que ela deu um ponto de partida ao trabalhar esses conteúdos. Nesse sentido, Toledo e Toledo (2009) consideram que a Geometria é um campo fértil para trabalhar com situações-problema, sobre as quais os alunos se interessam bastante, pois as noções geométricas contribuem para a aprendizagem de números e medidas, além de estimular as crianças a identificar irregularidades, entre outros.

\subsection{Análise do questionário com os alunos}

Normalmente, as vozes dos alunos não são ouvidas ao longo do processo educativo. No entanto, sabemos que suas histórias de vida e o que percebem sobre as diferentes questões que circunscrevem o espaço escolar, como nos evidenciam Silva e Passos (2016, 2020), são importantes e precisam ser consideradas. Por esse motivo, queríamos saber o que entendem os estudantes sobre a Matemática e ludicidade.

Em relação à Matemática, a maioria respondeu que a disciplina está presente em todos os lugares. Nota-se que eles não têm a Matemática como algo distante do seu fazer cotidiano, semelhante ao que nos apresentou a professora. A aluna Bruna ${ }^{7}$, por exemplo, afirmou que a "Matemática é uma das poucas disciplinas presentes em tudo que a gente vê". Já Pedro responde que a Matemática "é bastante utilizada no nosso dia a dia, em tudo que fazemos necessitamos da Matemática". A esse respeito, a BNCC (BRASIL, 2017) apresenta que aprender Matemática é uma das maneiras de compreender e atuar no mundo e esse conhecimento é fruto da construção humana, a partir de sua interação com o contexto natural, social e cultural.

Ao questionarmos se gostam da disciplina de Matemática, três, dos cinco alunos,

\footnotetext{
7 Tendo em vista as questões éticas da pesquisa sinalizamos que todos os nomes são fictícios.
} 
responderam que sim. A exemplo de algumas respostas apresentadas, está a da estudante Bruna que afirma "não, porque é muito complicada, quebra muito a Cabeça". Já Fernanda responde que "sim. Porque ela é uma disciplina muito boa e fácil de aprender, se a gente prestar atenção nas aulas". Percebe-se pelas respostas, que duas alunas não gostam de Matemática e apresentam como motivo o fato de ser complicada. Os demais, no entanto, gostam da disciplina por encontrar nela alguma utilidade.

Mas o que leva os estudantes a construir tais percepções a respeito da Matemática? Claro que eles tiveram contato com a Matemática de formas diversas, tendo em vista que possuem histórias de vida diferentes. Podem, por exemplo, ter estudado em escolas distintas e a aproximação ter se dado de forma desigual.

No entanto, por que apresentam percepções diferentes se estão com a mesma professora? Nesse caso, é importante levar em consideração que os estudantes possuem ritmos e tipos de aprendizagem diversos, como evidenciou a professora ao longo das respostas em seu questionário. No caso, a aprendizagem pode estar em processo e não nos cabe julgamento e, muito menos, ser imediatista.

Ao serem questionados sobre as metodologias usadas pela professora, três, dos cinco estudantes responderam que a professor diversifica suas metodologias. A esse respeito, Bruna relata que "sim. Várias vezes ela modifica as aulas". Pedro também concorda com Bruna ao destacar que "sim, já trabalhamos com jogos utilizando as quatro operações". Sabe-se que a utilização de métodos diversificados em sala de aula, quando utilizados de forma planejada, traz benefícios, como destaca Moura (2011) ao considerar que os jogos, quando passam a ter um caráter de ensino, são considerados promotores de aprendizagem.

Quando os alunos respondem sobre o que é lúdico para eles, fica perceptível que sempre fazem a relação do lúdico com brincadeiras e com jogos. Bruna afirma que "lúdico para mim é ilustrar a aula, modificar com brincadeiras, jogos e outras". Nessa resposta fica perceptível que ao responder "e outras" é porque percebe que o lúdico vai além de apenas brincadeiras e jogos, e o considera como um método que alia a diversão com o prazer.

Lucas também diz que o "lúdico são as coisas que os professores trabalham diferente. Por exemplo, fazer brincadeiras com dados, jogos de cartazes, e que o aluno goste dessa forma e aprenda". Ao responder "são as coisas que os professores trabalham diferente", percebe-se que faz uma ligação entre a sala de aula com o lúdico, com divertimento e, também, 
relata o gosto pelo lúdico quando responde que o aluno gosta dessa forma.

A resposta de Fernanda a respeito do lúdico é bem parecida com a de Lucas, pois diz que "é uma aula diferente que ao mesmo tempo em que a gente aprende, se diverte. Uma aula que o professor da em forma de brincadeira". Observa-se que Fernanda também relaciona 0 lúdico com uma aula diferente, em que os estudantes aprendem se divertindo. Ao nos dizer que lúdico é quando o professor dá uma aula em forma de brincadeira, lembramos do que nos apresenta Fortuna (2001) sobre uma aula ludicamente inspirada ser aquela em que está presente as características do brincar, como é percebido igualmente pela estudante.

Em outra questão ficou perceptível que a professora, nas aulas de Matemática, já trabalhou com metodologias diversificadas. A esse respeito, Pedro relatou, sobre as atividades desenvolvidas por sua professora, que gostou e que ela "fez com que eu tomasse mais conhecimento, porque os jogos nos dá mais vontade de aprender". Fernanda respondeu que "sim. Eu gostei muito, foi uma aula legal, mais passou muito rápido, eu aprendi mais do que nas outras aulas" e Bruna afirmou que "gostei porque a gente acaba se influenciando e acaba aprendendo mais".

Em todas as respostas citadas, o que fica evidenciado é o "sim" para o fato de que a professora já utilizou metodologias lúdicas e que eles gostaram e aprenderam bastante. Para Smole, Diniz e Milani (2007), quando os alunos jogam, eles têm a oportunidade de resolver problemas e investigar e descobrir a melhor jogada, estabelecendo uma relação entre o jogo e os conceitos de aprendizagem.

Ao perguntar se a professora já havia trabalhado algum conteúdo de Geometria, alguns responderam que já tinham visto algum conteúdo, outros disseram que se lembrar. Fernanda contou que "sim, ela já trabalhou esse assunto". A aluna Carol descreveu "Sim, o conteúdo é a reta". Já Bruna respondeu que: "não me lembro". De acordo com Lorenzato (2011), o grande objetivo da Geometria é fazer com que a criança passe do espaço em que vive para o espaço pensado. Em outras palavras, é a passagem do concreto ao abstrato.

\subsection{Análise do questionário depois das oficinas}

Depois da realização das oficinas, na qual se usou de diversos instrumentos potencialmente lúdicos, apresentamos um questionário para os alunos objetivando saber como 
entenderam 0 trabalho realizado e se as suas percepções após a vivência das atividades propostas se alteraram.

A primeira pergunta do segundo questionário era a mesma do anterior e interrogava sobre o que é o lúdico. Percebemos, por meio das respostas apresentadas, que alguns estudantes mudaram a sua percepção. 0 exemplo disso foi a aluna Fernanda que quando respondeu 0 primeiro questionário afirmou se tratar de "aula [em] que o professor dá em forma de brincadeira". Já Lucas, no primeiro questionário, respondeu que é "fazer brincadeiras". Após as oficinas, eles perceberam que o lúdico não está necessariamente relacionado às brincadeiras, mas tudo aquilo que traz divertimento e promove prazer.

Quando questionada novamente, Fernanda relata que "o lúdico pode ser muito mais que apenas brincadeira, pode ser atividades que o professor dá que chama a atenção do aluno". Já Lucas responde que "pode ser qualquer coisa que o professor dá de diferente que os alunos gostam e aprendam se divertindo".

O contato com as diversas formas de manifestação do lúdico, por meio das atividades propostas nas oficinas, de alguma forma os fizeram ampliar o olhar a respeito de tal metodologia e perceber a ludicidade de uma forma diferente. Sabemos que, no dia a dia da sala de aula, as diferentes atividades propostas pelo professor ajudam a constituir o que os estudantes entendem por Matemática e por Ludicidade, por exemplo.

Quando perguntamos se gostaram da metodologia utilizada nas oficinas, todos os cinco responderam que sim. Lucas, por exemplo, afirmou que "sim. Eu gostei porque a gente aprendeu coisas novas, fizemos descobertas maneiras de trabalhar Matemática”. Já Fernanda relatou que "sim, eu gostei muito as aulas foram bem legais, mas passou muito rápido, mesmo assim aprendi mais do que nas outras aulas". Nessa direção, Smole, Diniz e Milani (2007) concordam que, por ter uma dimensão lúdica, o jogar pode ser visto como uma das bases que desenvolve o espírito construtivo, a imaginação, a capacidade de sistematização e a capacidade de interagir socialmente.

Ao perguntar se as atividades propostas favoreceram a aprendizagem e o raciocínio, todos também relataram que sim. Bruna destaca que "a gente acaba se influenciando mais e acaba aprendendo mais". Pedro aponta que "sim, fez com que eu tomasse mais conhecimento, porque os jogos nos dá mais vontade de aprender".

Quando questionados se depois da realização das oficinas eles compreenderam melhor 
sobre Geometria, em especial sobre os sólidos geométricos, afirmaram que sim. Bruna, no primeiro questionário respondeu que não se lembrava se já tinha estudado sobre Geometria, mas no segundo questionário, falou que "a minha professora já trabalhou esse conteúdo, mas como foi uma aula normal eu nem me lembrava, agora com essa oficina eu nunca vou esquecer esses conteúdos". A esse respeito, Kaleff (1994) defende que as atividades que são encaradas como divertimentos são importantes não só para o desenvolvimento da intuição espacial e de habilidades de visualização, desenho, interpretação e construção, mas tem relação com a formação do pensamento geométrico dedutivo.

Por meio das respostas desse questionário, percebemos que, depois de realizadas as oficinas, os alunos mudaram algumas percepções a respeito do lúdico, reconhecendo ainda mais sua importância. Dessa forma, o modo como vivenciamos a prática pedagógica no ensino de Matemática pode promover ressignificações, não só de conceitos, mas de percepção, o que consiste o desafio na formação do professor em promover outras possibilidades em sua sala de aula, para além daquelas cristalizadas em sua formação.

\section{Algumas considerações}

Ensinar Geometria é importante porque é um conteúdo que se encontra presente no cotidiano dos alunos. Convivemos diariamente com os conceitos geométricos, como, por exemplo, a ideia de altura, largura, perímetro, área, volume e muitos outros. Abordar esses conceitos, partindo de uma abordagem lúdica, pode contribuir ainda mais para a aprendizagem do aluno e para o repertório de práticas do professor.

Tendo como base a pesquisa bibliográfica realizada para escrever a discussão teórica e a experiência empírica, ficou perceptível que quando o lúdico é trabalhado de forma adequada e bem planejada contribui para a aprendizagem dos alunos, fazendo com que se tornem, de certa maneira, pessoas com mais autonomia para matematizar.

Nesse trabalho, podemos ainda refletir quanto a ludicidade pode ser uma ferramenta que contribui para o ensino e para a aprendizagem, principalmente se tratando da disciplina de Matemática, considerada pela maioria um "bicho de sete cabeças". Por isso, o lúdico é tão importante, pois vem propiciar aos alunos um ambiente agradável, no qual as estratégias didáticas metodológicas estão sempre atreladas a propostas mais dinâmicas, divertidas e prazerosas. 
Cabe à universidade repensar, também, seus cursos de formação de professores buscando incluir o lúdico como aspecto importante do ensino, principalmente percebendo-o na sua dimensão humana, articuladora de saberes necessários à docência e constituintes da identidade do futuro professor.

\section{Referências}

ALMEIDA, Paulo Nunes de. Educação lúdica. São Paulo: Loyola, 1998.

ALVES, Eva Maria Siqueira. A Ludicidade e o ensino de Matemática. Campinas: Papirus, 2001.

BARDIN, Laurence. Análise de conteúdo. Tradução de Luís Antero Neto e Augusto Pinheiro. Lisboa: Edições 70, 1977.

BERG, Bruce L. Qualitative research methods for the social sciences. Long Beach: California State University, 2000.

BRASIL. Ministério da Educação. Secretaria da Educação Básica. Base Nacional Comum Curricular. Educação Infantil e Ensino Fundamental. Brasília: MEC/SEB, 2017.

D’AMBRÓSIO, Ubiratan. Educação Matemática: da teoria à prática. Campinas: Papirus, 1996.

D'AMBROSIO, Beatriz Silva. Formação de professores de Matemática para o século XXI: o grande desafio. Pro-Posições, Campinas, v. 4 n. 1 [10], p. 35-41, mar. 1993.

D’AMBRÓSIO, Ubiratan. Etnomatemática: arte ou técnica de explicar ou conhecer. 5. ed. São Paulo: Ática, 1998.

FERNANDES, Elsa. O trabalho cooperativo num contexto de sala de aula. Análise Psicológica, Lisboa, v. 15, n. 14, p. 563-572, dez. 1997.

FIORENTINI, Dario. MIORIM, Maria Angela. Uma reflexão sobre o uso de materiais concretos e jogos no ensino da Matemática. Boletim SBEM, São Paulo, v. 4, n. 7, p. 5-10, jul./ago. 1990.

FORTUNA, Tania Ramos. Formando professores na universidade para brincar. In: SANTOS, Santa Marli Pires dos. (Org.). A ludicidade como Ciência. Petrópolis: Vozes, 2001, p. 115-119.

GIL, Antonio Carlos. Como elaborar projetos de pesquisa. São Paulo: Atlas, 2002.

HUIZINGA, Johan. Homo Ludens: o jogo como elemento da cultura. Tradução de João Paulo Monteiro. 7 ed. São Paulo: Perspectiva. 2012.

IMBERNÓN, Francisco. Formação docente e profissional: formar-se para a mudança e a incerteza. Tradução de Juliana dos Santos Padilha. 7. ed. São Paulo, Cortez, 2009.

KALEFF, Ana. Tomando o ensino de Geometria em nossas mãos. Educação Matemática em Revista, Blumenau, n. 2, p. 19-25, 1994. 
LOREZANTO, Sergio. (Org). O Laboratório de Ensino de Matemática na formação de professores. 3. ed. Campinas: Autores associados, 2010.

LORENZATO, Sergio. Educação Infantil e percepção matemática. 3. ed. Campinas: Autores Associados, 2011.

MOURA, Manoel Oriosvaldo de. A séria busca no jogo: do lúdico na Matemática. In: KISHIMOTO, Tizuko. Jogo, brinquedo, brincadeira e a educação. São Paulo: Cortez, 2011, p. 81-97.

MUNIZ, Cristiano Alberto. Educação lúdica da Matemática, Educação Matemática lúdica. In: SILVA, Américo Junior Nunes da; TEIXEIRA, Heurisgleides Sousa. (Org.). Ludicidade, formação de professores e Educação Matemática em diálogo. Curitiba: Appris, 2016, p. 12-28.

PENNA, Antônio Gomes. Percepção e realidade: introdução ao estudo da atividade perceptiva. Rio de Janeiro: Imago, 1997.

SÁ, Antônio Villar Marques de; SILVA, Américo Junior Nunes; BRAGA, Maria Dalvirene; SILVA, Onã. (Org.). Ludicidade e suas interfaces. Brasília: Líber livros, 2013.

SANTOS, Santa Marli Pires dos; CRUZ, Dulce Regina Mesquita. O lúdico na formação do educador. In: SANTOS, Santa Marli Pires dos. (Org.). O lúdico na formação do educador. 9. ed. Campinas: Autores Associados, 2011, p. 7-18.

SILVA, Américo Junior Nunes da. A ludicidade no laboratório: considerações sobre a formação do futuro professor de Matemática. Curitiba: Editora CRV, 2014.

SILVA, Américo Junior Nunes da. PASSOS, Carmen Lúcia Brancaglion. Querido diário: o que dizem as narrativas sobre a formação e a futura prática do professor que ensinará Matemática nos Anos Iniciais. Hipátia, São Paulo, v. 1, n. 1, p. 46-57, 2016.

SILVA, Américo Junior Nunes da. PASSOS, Carmen Lúcia Brancaglion. Formação do professor que ensina Matemática, ludicidade e narrativas: o que se pesquisou no Brasil. Reveduc, São Carlos, v. 14, p. 1-18, 2020.

SILVA, Américo Junior Nunes da; NASCIMENTO, Ana Maria Porto do; MUNIZ, Cristiano Alberto. O necessário olhar do professor sobre a produção matemática das crianças nos Anos Iniciais. Educação Matemática em Revista, Brasília, n. 54, p. 48-55, jul. 2017.

SILVA, Jonas Laranjeira Saraiva da; EVANGELISTA, Joil Ramos; SANTOS, Rafael Batista dos; MENDES, Paulo Muniz. Matemática lúdica - Ensino Fundamental e Médio. Educação em Foco, Amparo, v. 6, n. 3, p. 26-36, maio 2013.

SMOLE, Katia Stocco; DINIZ, Maria Ignez; MILANI, Estela. Cadernos do Mathema: jogos de Matemática do $6^{\circ}$ ao $9^{\circ}$ ano. Porto Alegre: Artmed 2007.

SOARES, Eduardo Sarquis. Ensinar Matemática: desafios e possibilidades. Belo Horizonte: Dimensão, 2009.

TOLEDO, Marilia Barros de Almeida; TOLEDO, Mauro de Almeida. Teoria e prática de Matemática: como dois e dois. São Paulo: FTD, 2009. 